\title{
ESTUdO DE MÉTODOS DE AUMENTO dE RESOLUÇÃo DE ESPECTROS DE FTIR PARA ANÁLISE DE ESTRUTURAS SECUNDÁRIAS DE PROTEÍNAS
}

\author{
Lucimara A. Forato \\ Instituto de Química de São Carlos - USP - Av. Dr. Carlos Botelho 1465 - CP 13560 - 970 - São Carlos - SP \\ Rubens Bernardes Filho e Luiz A. Colnago \\ Instituto de Química de São Carlos - USP - Av. Dr. Carlos Botelho 1465 - CP 13560 - 970 - São Carlos - SP \\ Centro Nacional de Pesquisa e Desenvolvimento da Instrumentação Agropecuária CNPDIA - EMBRAPA \\ R. XV de Novembro 1452 - CP 13560-970 - São Carlos - SP
}

Recebido em 31/1/97; aceito em 8/10/97

\begin{abstract}
STUDY OF RESOLUTION ENHANCEMENT METHODS FOR ANALYSIS OF SECONDARY STRUCTURE OF PROTEINS BY FTIR. The FTIR spectroscopy has been used to quantify the secondary structures of proteins, using amide I band $\left(1600-1700 \mathrm{~cm}^{-1}\right)$. The resolution enhancement methods have been used to resolve the individual components of this band that correlate to the secondary structure. In this paper we discuss the methods of derivative, Fourier deconvolution and fitting with simulated spectra. The results shows that they have serious problems and can be used only as a qualitative or semiquatitative method.
\end{abstract}

Keywords: methods of resolution enhancement; FTIR; protein.

\section{INTRODUÇÃO}

As técnicas utilizadas para a determinação das estruturas tridimensionais de proteínas em alta resolução são a cristalografia de raios X e a Ressonância Magnética Nuclear (RMN) ${ }^{1}$. A técnica de raios $\mathrm{X}$ exige monocristais de alta qualidade, o que não é trivial de obter, principalmente no caso de proteínas de membranas ${ }^{1-5}$. Já a RMN se restringe a proteínas de baixo peso molecular ${ }^{3}$. Dessa forma, técnicas como dicroísmo circular (CD) e as espectroscopias Raman e Infravermelho com transformada de Fourier (FTIR) têm sido utilizadas para quantificar os tipos de estruturas secundárias de proteínas (ESP) presentes nas amostras sem, contudo, determinar as suas localizações ${ }^{3-5}$. As principais vantagens dessas técnicas são a rapidez na realização das medidas, o fato de não haver restrições quanto ao peso molecular da proteína em estudo e a não necessidade de cristais.

Dentre essas técnicas o FTIR vêm apresentando grandes avan$\operatorname{ços}^{2,3,4}$ pois além de ser uma técnica rápida, permite que a amostra seja analisada em vários ambientes como solução aquosa ${ }^{3,4,5}$, sólido amorfo $^{6}$ ou cristalino ${ }^{3}$, filmes ${ }^{3,6,7,8}$, membranas ${ }^{3,4,5,9}$, pastilhas de $\mathrm{KBr}^{10}$, além dos espectrômetros de FTIR serem mais facilmente encontrados do que os de Raman e Dicroísmo Circular.

A maioria das informações de FTIR sobre as estruturas secundárias das proteínas ( $\alpha$-hélice, folhas $\beta$, voltas $\beta$ e irregulares) é obtida da análise da banda de amida I, que ocorre na região de $1700-1600 \mathrm{~cm}^{-1}$. Esta banda é devida principalmente ao estiramento da ligação $\mathrm{C}=\mathrm{O}$ da ligação peptídica e é sensível às diferentes conformações das ESP.

A atribuição dos picos da banda de amida I às diferentes estruturas secundárias é encontrada na literatura ${ }^{11}$. Para $\alpha$ hélices em solução aquosa a absorção ocorre em $1656 \mathrm{~cm}^{-1}$; para as folhas $\beta$ em 1624, 1627, 1632, 1638 e $1642 \mathrm{~cm}^{-1}$, voltas $\beta$ em 1666, 1672, 1680, $1688 \mathrm{~cm}^{-1}$ e as irregulares em $1650 \mathrm{~cm}^{-1}$. Como todos esses sinais podem estar presen-

E-mail:lucimara@cnpdia.embrapa.br;

E-mail:rubens@cnpdia.embrapa.br;

E-mail:colnago@cnpdia.embrapa.br tes numa única proteína, a banda de amida I é uma banda altamente complexa, onde esses componentes não são observados individualmente ${ }^{5}$. Assim o processo de quantificação das ESP a partir de espectros de FTIR envolve o uso de métodos matemáticos como os de aumento de resolução e reconhecimento de padrões ${ }^{3-5,6,8}$. Desses métodos os de aumento de resolução são os mais usados ${ }^{4}$ e serão analisados neste trabalho.

Os métodos de aumento de resolução se baseiam na separação dos picos que compõem a banda de amida I e na correlação de suas áreas ou intensidades com as estruturas secundárias. Esses métodos incluem o uso de derivadas, a deconvolução de Fourier e ajuste do sinal original e deconvoluído ${ }^{4,5,10-12}$.

As primeiras tentativas de quantificação das estruturas secundárias se basearam no ajuste ("fitting") do sinal $1^{5,13,14}$. Esse método não foi muito usado, por dificuldades na obtenção dos principais parâmetros de entrada para o ajuste, que são o número e a posição dos picos ${ }^{4}$.

O primeiro trabalho usando as derivadas dos espectros de proteínas foi publicado por Susi \& Byler, em $1983^{15}$. Eles obtiveram a segunda derivada das bandas de amida I e II da ribonuclease $A$, hemoglobina e $\beta$-lactoglobulina A (nativa e desnaturada), em solução de $\mathrm{D}_{2} \mathrm{O}$. Apesar desse método também ter sido usado por vários outros autores ${ }^{3,4,5,18}$ só Dong et $\mathrm{al}^{8,16,17}$ apresentaram um estudo detalhado de como usar a segunda derivada na quantificação de ESP. Isso porque alguns autores consideram as derivadas como métodos qualitativos ou semiquantitativos ${ }^{7}$.

Outro método é a deconvolução de Fourier ${ }^{3,4,5,18,19}$, que consiste na convolução do sinal de infravermelho (IV) com uma função filtro, no domínio de Fourier onde é apenas uma multiplicação. A função filtro mais usada em espectros de IV de proteínas é a desenvolvida por Kauppinen e colaboradores em $1981^{19}$ (equação 4). Com aplicação dessa função nos interferogramas, consegue-se reduzir a largura dos sinais.

Assim como nas derivadas, usaram-se inicialmente as intensidades dos picos deconvoluídos para a quantificação das $\mathrm{ESP}^{9,20}$. Essa técnica não foi muito usada na quantificação, pois as intensidades são distorcidas com a aplicação das funções filtro ${ }^{19}$. 
A combinação do método de deconvolução de Fourier com o ajuste do sinal, desenvolvido por Byler \& Susi ${ }^{11}$ em 1986, foi a metodologia que revolucionou as aplicações do FTIR em proteínas e atraiu uma grande atenção para a potencialidade da técnica. Nesse estudo, além da deconvolução de Fourier, foi usada a segunda derivada dos espectros para selecionar o número e a posição dos picos. O ajuste foi feito com curvas gaussianas, com a análise de 21 proteínas globulares em água deuterada, obtendo-se um desvio de apenas $2,5 \%$, se comparado aos dados obtidos de raios $\mathrm{X}$.

Outra opção encontrada na literatura tem sido o uso do ajuste do sinal original ${ }^{5,8}$, com a ajuda dos métodos de aumento de resolução, derivada ou deconvolução de Fourier, para a definição do número e posição dos picos.

Como a capacidade de quantificação das ESP por métodos de aumento de resolução tem gerado controvérsias ${ }^{21}$, decidiuse estudar sua validade utilizando espectros simulados onde há total controle sobre os parâmetros espectrais.

\section{MATERIAIS E MÉTODOS}

Os espectros foram simulados em programa desenvolvido em ambiente Matlab. Usou-se função lorentziana, considerando-se que as absorções do infravermelho são desse tipo, com pouca contribuição de gaussiana ${ }^{19,22,23}$. A função lorentziana está descrita pela equação (1).

$$
A=\frac{A_{0} \gamma^{2}}{\left(\gamma^{2}+\left(v-v_{0}\right)^{2}\right)}
$$

onde: $\mathrm{A}_{0}=$ intensidade do sinal; $\gamma=$ meia largura na meia altu$\mathrm{ra} ; \mathrm{v}=$ faixa espectral; $v_{0}=$ freqüência do sinal.

Os espectros foram simulados, com resolução digital de 2 $\mathrm{cm}^{-1}$ e a faixa espectral de 1550 a $1750 \mathrm{~cm}^{-1}$. Os cálculos das derivadas e os ajustes foram feitos no programa Origin 4.0. A deconvolução de Fourier foi realizada em programa desenvolvido em ambiente MatLab. Neste programa faz-se a transformada inversa de Fourier do sinal simulado. Multiplica-se o resultado dessa transformada com a função de Kauppinen e colaboradores $^{19}$, equação 4 e faz-se a transformada de Fourier desse resultado para obter o espectro deconvoluído.

$\mathrm{O}$ número e posição dos picos para os ajustes foram fornecidos pela segunda derivada, as formas de linhas utilizadas foram lorentzianas e a largura variou livremente durante o ajuste.

Para os sinais simulados de proteínas usaram-se valores médios de número de onda observados em proteínas ricas em $\alpha$-hélice e folhas $\beta^{11,12}$. Para o sinal de uma proteína rica em $\alpha$-hélice utilizaram-se 8 sinais lorentzianos em 1620, 1633, 1639, 1642, 1650, 1656,1666 e $1680 \mathrm{~cm}^{-1}, 10 \mathrm{~cm}^{-1}$ de meia-largura na meia altura e área e intensidades iguais exceto o pico em 1656, que tem área/ intensidade dez vezes maior. Para o sinal simulado de uma proteína rica em folhas $\beta$, usaram-se 11 sinais lorentzianos em 1623, 1627 , $1632,1639,1642,1650,1656,1665,1675,1684$ e $1695 \mathrm{~cm}^{-1}$, com $10 \mathrm{~cm}^{-1}$ de meia-largura na meia altura e com mesma intensidade.

\section{RESULTADOS E DISCUSSÃO}

$\mathrm{Na}$ avaliação da quantificação dos métodos de aumento de resolução usaram-se espectros simulados, pois permitem o controle sobre todos os parâmetros usados. Nos espectros reais isso não é possível, pois podem ocorrer distorções instrumentais, interferência dos solventes, impurezas, ruídos, bandas de sobreposição, entre outros ${ }^{21}$. Os espectros simulados tem sido usados para verificação de metodologias ${ }^{21}$.

É importante salientar alguns aspectos sobre as técnicas de aumento de resolução:

i. O processamento do sinal não aumenta a resolução instru- mental; o que faz é aumentar o grau de visualização dos picos individuais.

ii. O aumento de resolução não introduz qualquer fenômeno físico novo.

iii. Os estreitamentos das bandas são obtidos com distorções das bandas originais e também levam à degradação da razão sinal/ruído.

iv. A quantificação baseada em aumento de resolução é dependente da relação das áreas e/ou intensidades relativas, e não dos valores absolutos.

\section{Derivação do Sinal}

A derivação dos sinais de FTIR vêm sendo usada desde 1983 em estudos de $\mathrm{ESP}^{3}$. Dong et $\mathrm{al}^{8,16,17}$, fizeram uma descrição detalhada do uso da segunda derivada como método quantitativo na determinação das ESP, e tem sido criticado por alguns autores ${ }^{4,7}$. Somente as derivadas pares (principalmente a segunda) tem sido usadas em estudos de $\operatorname{ESP}^{4}$.

Como o sinal de FTIR é digital, com resolução finita e bem mais complexo, a sua derivada é calculada numericamente e o algoritmo mais usado é o de Savitzky-Golay ${ }^{11,15,18}$.

$\mathrm{Na}$ figura 1, tem-se um sinal simulado, onde a aplicação tanto da segunda como da quarta derivadas reduzem a largura do sinal. $\mathrm{O}$ inconveniente deste processamento é a presença de lobos laterais que distorcem a base do sinal. Como o uso de quarta derivada, que causa maior redução na largura de linha, é muito restrito por necessitar de razão sinal/ ruído muito alta ${ }^{15,24}$, a segunda derivada será analisada com mais detalhes.

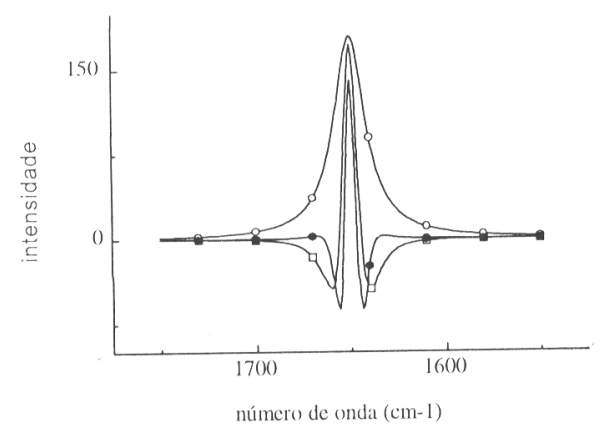

Figura 1. Sinal lorentziano em $1650 \mathrm{~cm}^{-1}$ com meia-largura em meia altura de $10 \mathrm{~cm}^{-1}(-0-), 2^{\underline{a}}$ derivada multiplicada por (-1) (- -) e $4^{\underline{a}}$ derivada (-๑-).

A meia largura da segunda derivada, $\gamma^{\prime \prime}$, está relacionada à meia largura do sinal original por ${ }^{15}$ :

$\gamma^{\prime \prime}=\left(\frac{1}{2.7}\right) \gamma$

Para um sinal composto de dois picos de mesma intensidade e $10 \mathrm{~cm}^{-1}$ de meia largura na meia altura, a distinção entre os dois picos pelas derivadas só começa a ser observada a partir de $8 \mathrm{~cm}^{-1}$ e $6 \mathrm{~cm}^{-1}$ de separação, para a segunda e quarta derivadas respectivamente. Para sinais com diferenças de intensidade como o da figura 2 , a distinção pela segunda e quarta derivadas só começa em 10 e $8 \mathrm{~cm}^{-1}$ respectivamente. Ou seja, a segunda derivada só distingue sinais com separação igual ou superior à sua meia largura na meia altura. Nesta figura podese notar a grande distorção do sinal de baixa intensidade. Além disso não há como definir com precisão uma linha de base tanto para o cálculo das intensidades e áreas. Esse problema não tem sido levado em consideração nos trabalhos publicados por Dong et $\mathrm{al}^{8,16,17}$. 


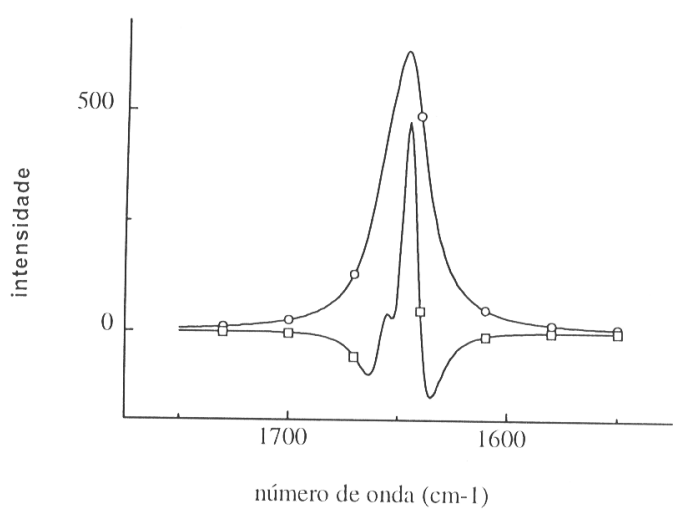

Figura 2. Sinal composto por dois picos com razão de intensidades $3: 1,10 \mathrm{~cm}^{-1}$ de meia largura na meia altura e centrados em 1645 e $1655 \mathrm{~cm}^{-1}$ respectivamente (-0-) e a $2^{\underline{a}}$ derivada (- $\left.\square-\right)$ do sinal multiplicada por (-1).

Um problema adicional é encontrado com o uso de derivadas quando as larguras de linhas dos sinais não são iguais. A intensidade da segunda derivada de um sinal lorentziano ${ }^{15}$ é dada por:

$$
I^{\prime \prime}=-\frac{2 I}{\left(2.7 \gamma^{\prime \prime}\right)^{2}}
$$

onde a intensidade da derivada do sinal é inversamente proporcional ao quadrado da meia largura original. Um exemplo desse efeito pode ser visto na figura 3 , onde foram simulados espec-

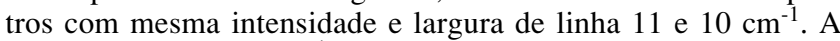
separação foi de $40 \mathrm{~cm}^{-1}$ para melhor visualização do problema. Pode-se notar que tanto a intensidade como a área do sinal mais largo, sofreram uma redução de $80 \%$ se comparado ao sinal mais estreito. A redução da relação da área será tanto maior quanto maior for a diferença de largura de linha entre os sinais.

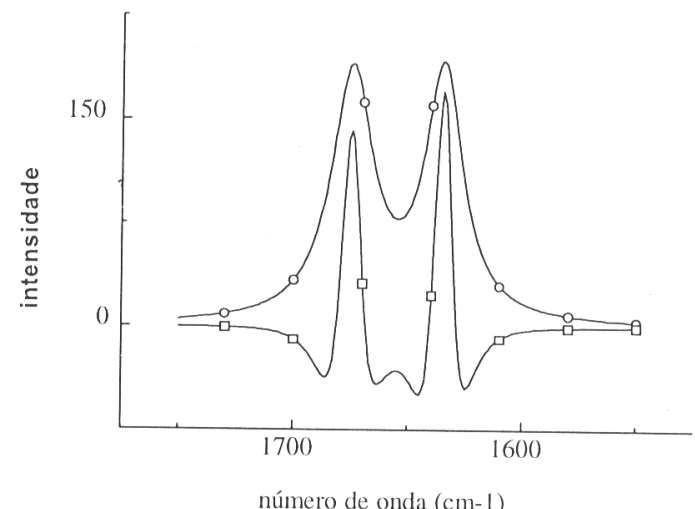

Figura 3. Sinal constituído de dois picos centrados em 1640 e 1680 $\mathrm{cm}^{-1}$, com intensidades iguais e meia-largura na meia altura de linhas de 10 e $11 \mathrm{~cm}^{-1}(-0-)$ e a $2^{a}$ derivada (-口-) multiplicada por (-1).

Com isso fica evidente que as derivadas só podem ser usadas em análises quantitativas quando as larguras de linha forem iguais e quando os sinais estiverem separados em números de onda maiores que suas meias larguras à meia altura e com pequenas diferenças de intensidade. Como em espectros reais de proteínas isso não é garantido, as derivadas só devem ser usadas em análises qualitativas ou semiquantitativas ${ }^{7}$.

\section{Deconvolução de Fourier}

A deconvolução de Fourier é outra técnica usada para reduzir a largura das bandas dos espectros. Esse procedimento é muito usado em espectroscopia de RMN tanto para aumento de resolução ou para melhoria da razão sinal/ruído ${ }^{3-5,9,19}$. A redução da largura do sinal é obtida com a convolução do espectro com uma função filtro do tipo passa alta ${ }^{19}$. Por facilitar o processamento, essa convolução é realizada no domínio de Fourier, onde é apenas uma multiplicação. Para isso obtém-se o interferograma a partir do espectro da proteína, com a transformada inversa de Fourier. Após a multiplicação do interferograma com a função filtro faz-se novamente a transformada de Fourier para obter o espectro com as linhas mais estreitas ${ }^{19}$.

As funções filtro do tipo passa alta são exponenciais crescentes do tipo exp $(\mathrm{x} \gamma)$, onde $\mathrm{x}$ é o retardamento em $\mathrm{cm}$ e $\gamma$ a meia largura a meia altura $\mathrm{em}^{-1}$. A sua utilização reduz o decaimento do interferograma reduzindo a largura de linha do espectro. Ao aumentar a resolução há um conseqüente aumento de ruído, pois no final do interferograma há uma grande redução da razão sinal/ruído. Essa função também aumenta o problema de truncagem causando o aparecimento de batimentos laterais no espectro. Ambos os problemas podem ser amenizados com a utilização de funções de apodização do sinal. Uma função (ff) que contempla as duas soluções (4) foi proposta por Kauppinen e colaboradores ${ }^{19}$ :

$f f=\left(1 \frac{x}{L}\right)^{2} \exp (2 \pi \gamma x)$

onde x é o retardamento em $\mathrm{cm}$; L é o ponto limite da função filtro em $\mathrm{cm}$; $\gamma$ é a largura de linha na meia altura $\mathrm{em} \mathrm{cm}^{-1}$.

Esta função representada na figura 4 é largamente usada em estudos de proteínas por FTIR ${ }^{3-7}$ e apresenta o crescimento exponencial necessário para o aumento de resolução bem como a apodização $(1-\mathrm{x} / \mathrm{L})$, fazendo com que o sinal retorne a zero, no ponto onde $\mathrm{L}=\mathrm{X}$. Multiplica-se também o interferograma por uma função boxcar, que tem valor 1 de zero a $\mathrm{L}$ e zero de $\mathrm{L}$ a $\mathrm{X}$, ou seja, é a substituição dos valores dos pontos de $\mathrm{L}$ a x por zero ${ }^{19}$.

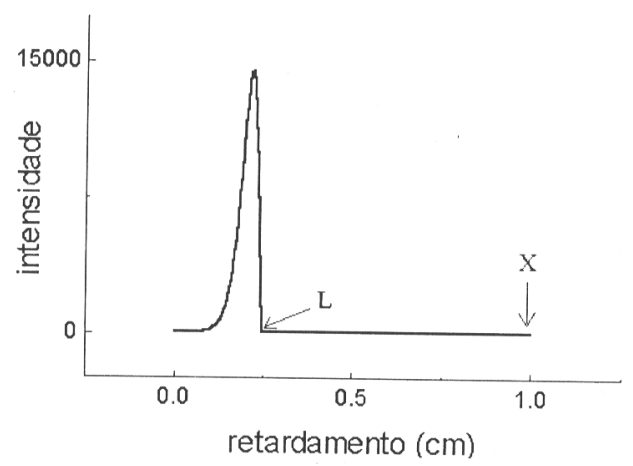

Figura 4. Função de Kauppinen e colaboradores, $L=0.25$ e $\gamma=10 \mathrm{~cm}^{-1}$

Diferentemente das derivadas, o sinal decorrente da deconvolução de Fourier (figura 5) não é muito distorcido e a redução da largura de linha pela deconvolução de Fourier é determinada pela escolha dos valores de $\gamma$ e/ou L. Isso pode ser um problema pois pode levar à sobredeconvolução do sinal (figura 6), onde aparecem os lobos laterais ${ }^{19}$, isto devido a utilização de um valor de $\gamma$ grande comparado à largura de linha do sinal $(\gamma=10)$.

Ao deconvoluir um espectro composto de sinais de mesma largura de linha, as intensidades e áreas relativas são mantidas (igual às derivadas). No entanto, quando as larguras de linha são diferentes, cada sinal tem sua intensidade reduzida por um fator inversamente proporcional à sua largura de linha, ou seja, os sinais mais largos ficam menos intensos, como nas derivadas ${ }^{10}$. O fator de redução depende dos valores de $\mathrm{L}$ e $\gamma$ usados. Por isso o uso das intensidades tem sido pouco aplicado na análise das ESP ${ }^{4}$. 


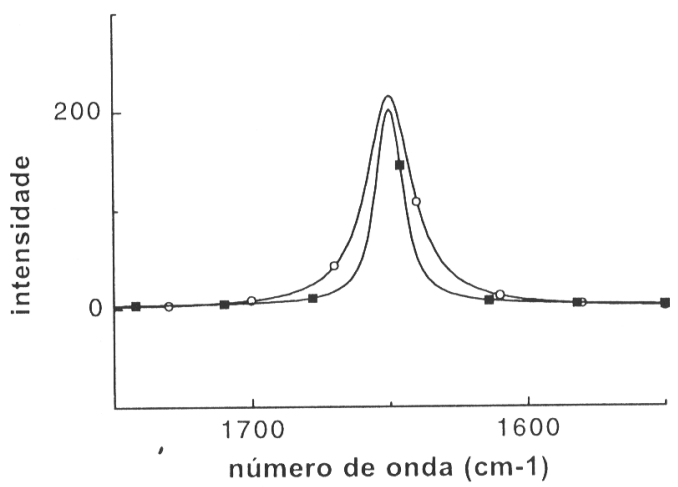

Figura 5. Sinal lorentziano com meia-largura em meia altura de 10 $\mathrm{cm}^{-1}$ (-0-) e após deconvolução com a função de Kauppinen e colaboradores, $L=0,15$ e $\gamma=10 \mathrm{~cm}^{-1}(-\boldsymbol{-})$.

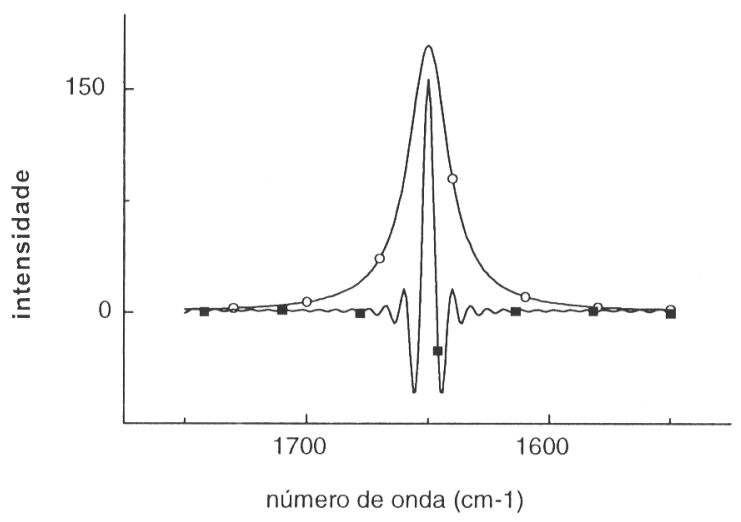

Figura 6. Sinal lorentziano com meia-largura na meia altura de 10 $\mathrm{cm}^{-1}\left(\mathrm{O}_{-}\right)$e após deconvolução com função de Kauppinen e colaboradores, $L=0,15$ e $\gamma=15 \mathrm{~cm}^{-1}$ (- - -).

Na figura 7, pode-se observar o efeito da deconvolução de dois sinais de mesma intensidade e largura de linha 11 e 10 $\mathrm{cm}^{-1}$, separados por $60 \mathrm{~cm}^{-1}$ (para facilitar a visualização).

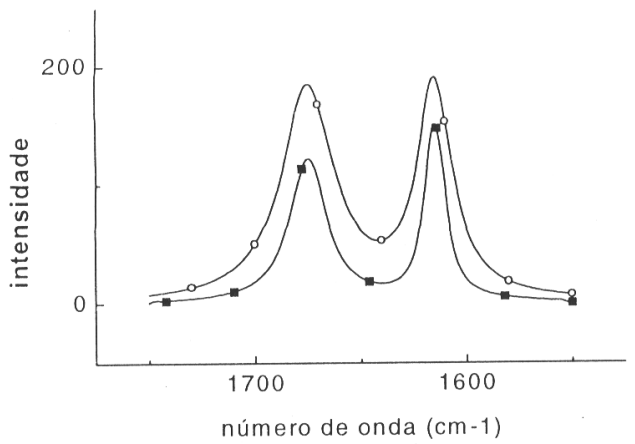

Figura 7. Sinal composto por um pico em $1620 \mathrm{~cm}^{-1}, \gamma=10 \mathrm{~cm}^{-1} e$ outro em $1680 \mathrm{~cm}^{-1} \mathrm{com} \gamma=11 \mathrm{~cm}^{-1}(-0-)$ e após deconvolução com função de Kauppinen e colaboradores, $L=0,15$ e $\gamma=10 \mathrm{~cm}^{-1}$ (-m-).

As linhas mais estreitas sofrem maior deconvolução (ficam proporcionalmente mais estreitas) que as linhas mais largas, porém a razão entre as áreas é mantida, diferentemente das derivadas.

Assim, é possível usar as áreas dos sinais deconvoluídos para as análises das ESP. Para a obtenção das áreas individuais em sinais altamente complexos como o de proteínas é necessário fazer o ajuste do sinal, para se obter as áreas dos sinais individuais.

\section{Ajuste do Sinal ("fitting")}

O ajuste é um processo de decomposição de um sinal complexo em seus componentes individuais, através da otimização pelo critério de mínimos quadrados, tendo como parâmetros de entrada o número e posição dos picos, forma e largura do sinal e uma linha de base ${ }^{11}$. $\mathrm{O}$ ajuste normalmente só produz resultados precisos quando a separação entre as bandas é maior que suas meias $\operatorname{larguras}^{22}$, o que não ocorre nos espectros de proteínas.

Como o método de deconvolução de Fourier reduz a largura de linha, sem distorcer as áreas relativas, o ajuste do sinal deconvoluído começou a ser largamente usado na quantificação das ESP de proteínas a partir do trabalho pioneiro de Susi \& Byler ${ }^{11}$.

$\mathrm{O}$ ajuste do sinal deconvoluído tem causado muita polêmica, com autores considerando-o como a melhor solução $7,21,24$ e outros defendendo o uso do ajuste do sinal original ${ }^{9,25}$.

Para os estudos de ajuste dos sinais originais e deconvoluídos, usaram-se dois tipos de sinais simulados, de uma banda de amida I composta por combinações das várias absorções de uma proteína rica em $\alpha$-hélice (figura 8 ) e outra rica em folhas $\beta$ (figura 9).

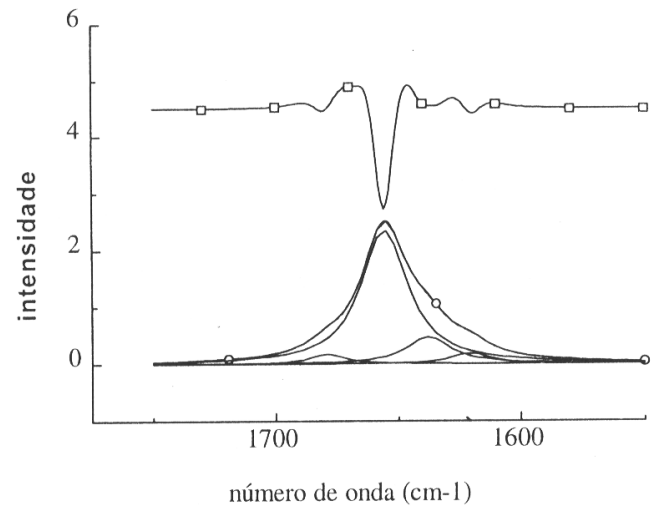

Figura 8. Sinal simulado (-0-) baseado em espectro de proteína com estrutura predominante em $\alpha$-hélice, $2^{\underline{a}}$ derivada (- - -) e os componentes individuais do ajuste (-).

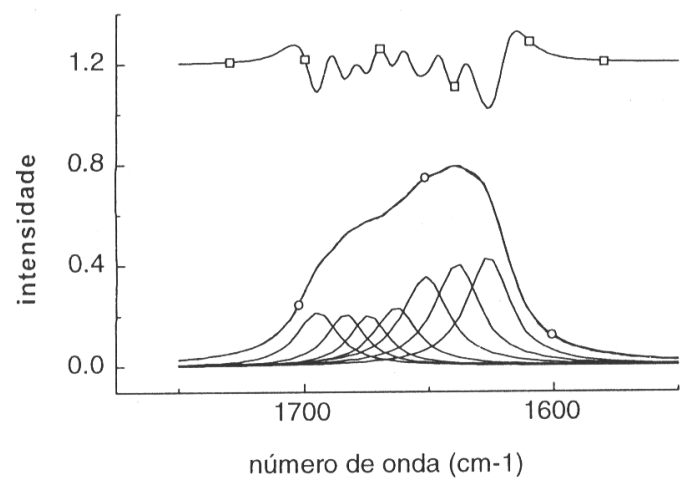

Figura 9. Sinal simulado (-0-) baseado em espectro de proteína com estrutura predominante em folha $\beta, 2^{a}$ derivada (-ם-) e os componentes individuais do ajuste (-).

Na figura 8 o espectro foi simulado com sinais de mesma largura de linha e intensidade. A exceção é o sinal em $1656 \mathrm{~cm}^{-1}$, que tem área dez vezes maior do que os outros picos e representa $60 \%$ da área total do sinal. Observa-se nessa figura que a segunda derivada só identificou 5 sinais, cujas posições foram usadas como parâmetros de entrada para o ajuste. Esse indicou que o sinal em $1656 \mathrm{~cm}^{-1}$ corresponde à $52 \%$ da área total e que as áreas dos outros sinais variaram em até 6 vezes entre si.

Esse tipo de resultado indica a dificuldade de usar o ajuste de espectros sobrepostos como o da banda de amida I de 
proteínas. No caso do sinal simulado para uma estrutura rica em folhas $\beta$ (figura 9) foram visualizados apenas sete sinais dos onze simulados. As áreas ou intensidades originais com intensidades iguais foram distorcidas em até $50 \%$.

O mesmo tipo de problema foi encontrado ao realizarem-se os ajustes dos mesmos sinais deconvoluídos com a função de Kauppinen e colaboradores. Para isso os espectros simulados foram processados pelo programa de deconvolução de Fourier. $\mathrm{Na}$ figura 10 tem-se o ajuste do sinal simulado (igual ao da figura 8) e deconvoluído, onde a derivada identifica somente 6 dos 8 picos existentes. Essa melhor resolução reflete o efeito da deconvolução de Fourier.

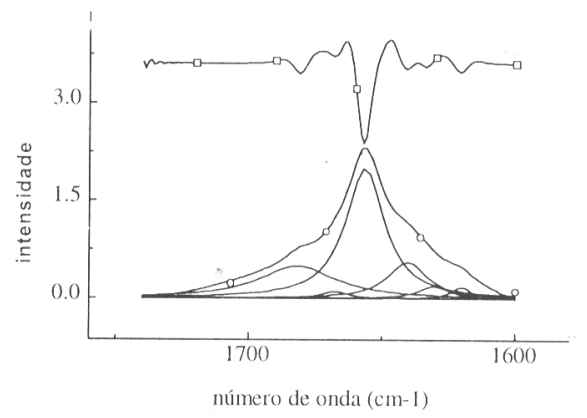

Figura 10. Sinal simulado como na figura 8 e deconvoluído com função de Kauppinen e colaboradores, $L=0,15$ e $\gamma=10 \mathrm{~cm}^{-1}(-0-), 2^{a}$ derivada (-ם-) e os componentes individuais do ajuste (-).

Na figura 11 tem-se o ajuste do sinal simulado (igual ao da figura 9) e deconvoluído. Neste caso também foi possível identificar com a segunda derivada um número maior de componentes (igual ao da figura 8) do que no ajuste do sinal original. Isso porém não foi suficiente para se obter a proporcionalidade entre as áreas dos picos.

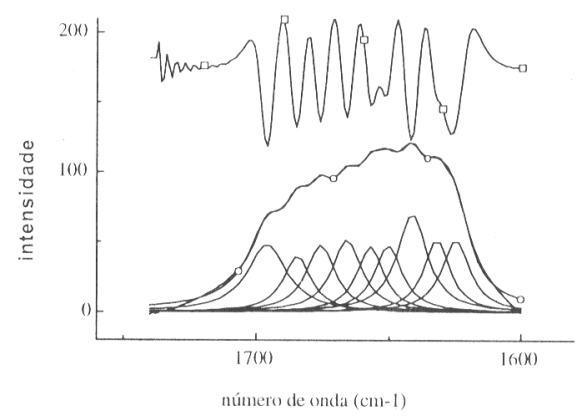

Figura 11. Sinal simulado como na figura 9 e deconvoluído com função de Kauppinen e colaboradores, $L=0,15$ e $\gamma=10 \mathrm{~cm}^{-1}(-0-), 2^{a}$ derivada (-口-) e os componentes individuais do ajuste (-).

Uma opção para melhorar o ajuste do sinal seria a utilização da quarta derivada ou aumentar o fator de aumento de resolução da deconvolução, para identificar o número e a posição dos picos. No entanto essa alternativa não tem muita aplicação em espectros reais uma vez que necessita de uma razão sinal/ruído da ordem de $10000 / 1^{24}$ e/ou pode levar à sobredeconvolução do sinal (figura 5).

\section{CONCLUSÕES}

A partir desses resultados pode-se concluir que não há confiabilidade no uso dos métodos de aumento de resolução na quantificação das ESP, uma vez que os sinais reais de proteínas são bem mais complexos do que os sinais simulados, devido às diferentes larguras de linha, não linearidade dos sinais, ruído e interferência do meio como sinais de solventes e vapor de água etc.

Esses métodos também estão sujeitos a interferências externas, uma vez que parâmetros como número e posição dos picos, fator de aumento de resolução, entre outros, podem ser escolhidos de modo a que conduzam a um resultado direcionado, ou seja, os métodos de aumento de resolução abordados não são confiáveis e só devem ser usados para fins de análises qualitativas ou semi quantitativas.

\section{AGRADECIMENTOS}

CNPq, EMBRAPA/CNPDIA e IQSC-USP.

\section{REFERÊNCIAS}

1. Voet, D.; Voet, J. "Biochemistry”, John Wiley \& Sons, New York, 1990.

2. Cantor, C. R.; Schimmel, P. R. "Biophysical Chemistry", Part I. W. H. Freeman Abd Company, San Francisco, 1980.

3. Mantsch, H. H.; Chapman, D.; "Infrared Spectroscopy of Biomolecules", John Wiley \& Sons, New York, 1995.

4. Surewicz, W. K.; Mantsch, H. H.; Chapman, D.; Biochemistry 1993, 32, 389.

5. Haris, P. I.; Chapman, D.; Trends in Biochem. sci. 1992, 17, 328.

6. Lamba, O. L.; Borchman, D.; Sinha, S. K.; Shah, J.; Renugopalakhrisnan, V.; Yappert, M. C.; Biochim. Biophys. Acta 1983, 1163, 113.

7. Jackson, M.; Mantsch, H. H.; Crit. Rev. Biochem. Mol. Biol. 1995, 30, 95.

8. Dong, A.; Matsura, J.; Allison, S. D.; Chrisman, E.; Manning, M. C.; Carpenter, J. F.; Biochemistry 1996, 35, 1450.

9. Wolkers, W. F.; Hatis, P. I.; Pistorius, A. M. A., Chapman, D.; Hemminga, M. A.; Biochemistry 1995, 34, 7825.

10. Forato, L. A.; Dissertação de Mestrado; IQSC/USP, São Carlos, 1996.

11. Byler, D. M.; Susi, H.; Biopolymers 1986, 25, 469.

12. Dong, A.; Huang, P.; Caughey. S.; Biochemistry 1990, 29, 3303.

13. Susi, H.; Timasheff, N.; Stevebs, L. J. Biol. Chem. 1967, 242, 5460 .

14. Elliot, A.; Ambrose, E. J.; Nature 1950, 165, 921.

15. SusI, H.; Byler, M.; Biochem. Biophys. Res. Comm. 1983, $115,391$.

16. Dong, A.; Huang, P.; Caughey, W. S.; Biochemistry 1992 , $31,182$.

17. Dong, A.; Prestrelski, S. J.; Dean allison, S.; Carpenter, J. F.; J. Pharmac. Sci. 1995, 84, 415.

18. Surewicz, W. K.; Mantsch, H. H.; Biochim. Biophys. Acta 1988, 952, 115.

19. Kauppinen, J. K.; Moffatt, D. J.; Mantsch, H. H.; Cameron, D. G.; Appl. Spectrosc. 1981, 35, 271.

20. Dousseau, F.; Pêzolet, M.; Biochemistry 1990, $29,8771$.

21. Pierce, J. A.; Jackson, R. S.; Every, K. W. Van; Griffiths, P. R.; Anal. Chem. 1990, 62, 477.

22. Tanfani, F.; Kochan, Z. Betoli, E.; Biopolymers 1995, $36,569$.

23 Hollósi, M.; Majer, Z. S.; Rónai, A. Z.; Magyar, A.; Medzhiradszky, K.; Holly, S.; Perczel.a; Fasman, G. D.; Biopolymers 1994, 34, 177.

24. Kauppinen, J. K.; Moffatt, D. J.; Mantsch, H. H.; Cameron, D. G.; Anal. Chem. 1981, 53, 1454.

25. Surewicz, W. K.; Mantsch, H. H.; Biochim. Biophys. Acta 1988, 952, 115 .

26. Forato, L. A.; Bernardes F. H, R.; Pessôa, J. D. C.; Colnago, L. A.; Anais do I Simpósio Nacional de Instrumentação Agropecuária 1996, 264. 